\section{Heritage status could safeguard fossil beds}

It is alarming that phosphate mining in Weng'an in southwest China has destroyed important Late Precambrian fossil beds from around 600 million years ago (Nature 544, 403; 2017). We suggest that scientists campaign for Weng'an to be recognized as a World Heritage Site under the United Nations Educational, Scientific and Cultural Organization (UNESCO). Developing such fossil sites for research and sustainable tourism could help to offset the costs of reducing mining activity.

Wengan county is poor - the average household income was $27 \%$ below the national average in 2015. Mining generates more than $60 \%$ of the county's annual revenue. Stopping unregulated mining would entail costly worker compensation and rehabilitation. Polluted sites would also need to be cleaned up.

Happily, lessons can be learnt from a fossil site some 700 kilometres away, the Chengjiang Cambrian Lagerstätte (see D.-G. Shu et al. Nature 414, 419-424; 2001). This saw a similar conflict around 17 years ago. After a lengthy dispute, the site was designated a UNESCO World Heritage Site in 2012, thanks to interventions by and support from domestic and international scientists. Mining stopped and more than 7 million tourists visited the site and nearby Fuxian Lake in 2016. The attraction last year generated about 3.8 billion yuan (US\$0.6 billion).

Hong Yang, Mingguo Ma Southwest University, China. Roger J. Flower University College London, UK. hongyanghy@gmail.com

\section{A rescue package for imperilled collection}

You recommend uniting universities' natural-history collections at regional hubs to protect them from financial constraints (see Nature 544, 137-138; 2017). The University of Michigan in Ann Arbor was initially reluctant to do this because it would have meant transferring full ownership of its mineral collection of some 15,000 specimens and irrevocably forfeiting their scientific, historical, educational and monetary value. We chose instead to set up the Michigan Mineral Alliance, in recognition of our responsibility to the public and to donors.

The alliance was created in 2015 by a perpetual legal agreement with Michigan Technological University in Houghton (see go.nature.com/2q7c5oh). It provides a shared, collaborative model for the benefit of both institutions. The mineral collection is now housed, curated, educationally exhibited and made available for research by the A. E. Seaman Mineral Museum of Michigan Tech, after uniting it with the museum's established collection.

Responsibilities for each specimen are defined; the most important are jointly managed. Should priorities change in the future, the co-ownership scheme permits return of the collection. Theodore J. Bornhorst A. E. Seaman Mineral Museum, Michigan Tech, Houghton, USA. Christopher J. Poulsen University of Michigan, Ann Arbor, USA.

Rodney C. Ewing Stanford University, California, USA. tjb@mtu.edu

\section{Rules for new species from live specimens}

The International Commission on Zoological Nomenclature (ICZN) has always permitted descriptions of new species without a preserved type specimen, but only under strict conditions (see ICZN Bull. Zool. Nomen. 73, 96-97; 2017). Now that this is more common, the taxonomic community must safeguard the system from abuse. If researchers plan to release a captive specimen that might be a new species, they should take high-definition photographs from all angles, concentrating on possible diagnostic characters. They must compile video, audio and geographical reference data, take blood or tissue samples and make precise measurements. Ideally, they should also analyse the specimen's DNA and compare it with that of putative sister taxa.

Taxonomists must consult peers on the authenticity of the new taxon and avoid species complexes of similar-looking related animals. Once the taxon is confirmed, they should describe one observed individual as the type (see go.nature. com/2qsatj), and explain why they could not secure a namebearing type specimen.

Before publishing in a peerreviewed journal, researchers need to ensure that their work complies with the ICZN Code and that the name is not already taken (see also Bull. Zool. Nomen. 65, 265-275; 2008). All data and raw photos must be placed in a public repository (such as Morphbank) and any physical evidence held in a museum.

Ethically responsible taxonomists do not alter photos, use others' photos without permission, or pre-emptively publish names for taxa others are working on.

Vazrick Nazari National Collection of Insects, Arachnids and Nematodes, Ottawa, Canada. Douglas Yanega University of California, Riverside. nazariv@agr.gc.ca

\section{Springer Nature's reply on fake review}

The publisher Springer Nature has already instituted the key process noted by Jian Gao and Tao Zhou to stamp out fake peer review (Nature 546, 33 (2017); Nature is editorially independent of Springer Nature). Since mid-2016 (or earlier for some journals), we have required authors who suggest unverified reviewers to supply an affiliation, institutional e-mail, ORCID ID and link to list of publications. We are also developing a rigorous reviewer-verification system for the whole of our business.

Earlier this year, we instituted the Springer Nature Research Integrity Group to deliver best practice and further training for staff and external editors. Springer Nature is committed to its role as guardian of the scientific record and to ensuring that all published content reaches appropriate editorial and ethical standards. We do not and will not hesitate to take action when problems are identified. Tamara Welschot Research Integrity Group, Springer Nature, Dordrecht, the Netherlands. tamara.welschot@springer.com

\section{Help to make food go further in Egypt}

You note that Egypt's population has "more than tripled in the past 50 years and is expected to surpass 150 million by 2050" (Nature 544, S14-S16; 2017). This rate of population growth would seem to be unsustainable, given that only $5 \%$ of Egypt's land is suitable for cultivation and that almost all of that land is already being farmed. Even with this intensive land use, the country still imports $40 \%$ of its food. I suggest that the problem is not so much that Egypt produces too little food, but rather that it is home to too many people.

Plans for closing the gap between food production and consumption - including drilling for fresh water under the Sahara and desalinating sea water - are impractical and prohibitively expensive (see go.nature.com/2ryeayb and go.nature.com/2qkacsw). In my view, more investment to reduce the birth rate is a better path to a sustainable balance between food production and consumption. Jeremy Nathans Johns Hopkins Medical School, Baltimore, USA. jnathans@jhmi.edu 